Revue d'histoire de l'Amérique française

REVUE D.HISTOIRE DE L'AMÉRIQUE FRANÇAISE

\title{
Chronique de la Fondation Lionel-Groulx
}

\section{Juliette Rémillard}

Volume 32, numéro 2, septembre 1978

URI : https://id.erudit.org/iderudit/303709ar

DOI : https://doi.org/10.7202/303709ar

Aller au sommaire du numéro

Éditeur(s)

Institut d'histoire de l'Amérique française

ISSN

0035-2357 (imprimé)

1492-1383 (numérique)

Découvrir la revue

Citer ce document

Rémillard, J. (1978). Chronique de la Fondation Lionel-Groulx. Revue d'histoire de l'Amérique française, 32(2), 310-311. https://doi.org/10.7202/303709ar d'utilisation que vous pouvez consulter en ligne.

https://apropos.erudit.org/fr/usagers/politique-dutilisation/ 


\section{CHRONIQUE DE LA FONDATION LIONEL-GROULX}

À l'occasion du centenaire de naissance du chanoine Lionel Groulx, le Comité de coordination des Fêtes du Centenaire lançait, au début de 1978, un grand concours national portant sur Lionel Groulx, prêtre, historien et homme d'action. Le concours s'adressait à tous les élèves du secondaire qui ont suivi le cours d'histoire nationale (475-412) et à tous les étudiants du collégial.

Ce concours, qui visait à sensibiliser les étudiants à leur histoire nationale tout en leur permettant une réflexion à caractère historique par le truchement d'un travail bien écrit, s'est avéré un franc succès. C'est dans le cadre du Congrès de la Société des professeurs d'histoire du Québec et en présence du Ministre Jacques-Yvan Morin que s'est déroulée la remise des prix aux gagnants du Concours LionelGroulx, tant au niveau collégial qu'au secondaire.

Sur les 137 copies parvenues en semi-finale, au niveau secondaire, 40 ont été retenues. Ces élèves ont pu bénéficier d'un séjour de quatre jours à Québec commandité par le Haut-Commissariat à la Jeunesse, aux Loisirs et aux Sports et les dix finalistes ont reçu des prix variant de $\$ 1000.00$ à $\$ 100$. Ce sont:

Suzanne Gagné $\quad \$ 1000$. France Gagnon $\$ 100$.

École Marie-de-la-Présentation Polyvalente du Cap-de-la-Madeleine

Richard Lemieux $\quad \$ 600$. Yves Guérin $\$ 100$.

Collège des Jésuites Polyvalente La Magdeleine

Stéphane Germain $\$ 400$. Claude Perreault $\$ 100$.

Polyvalente Antoine-Brossard Polyvalente Benoit-Vachon

Julie Latour

$\$ 300$.

Jacques Ramsay

$\$ 100$.

Polyvalente Daniel Johnson

Séminaire de Sherbrooke

Pierrette Clément

$\$ 200$.

Luc Mercure

$\$ 100$.

Polyvalente «Le Tournesol» Polyvalente Jean-Baptiste Meilleur 
Un prix spécial de $\$ 1000.00$ a été attribué à Monsieur Jean Sirois de la Polyvalente J. H. Leclerc qui avait suivi le cours secondaire, mais qui dépassait les critères de l'âge requis.

La Fondation Lionel-Groulx, représentée par le Père Richard Arès, s.j., décernait les prix au collégial à:

Christiane Huot

Petit Séminaire de Québec

$\$ 1000$. Hélène Bard

Joanne Bourassa

CEGEP de Valleyfield

$\$ 600$. Daniel Veilleux

Collège de St-Félicien

$\$ 100$.

Danielle Léger

CEGEP de Valleyfield

$\$ 400$. Jacques LaBerge

CEGEP Limoilou

Dominique-Esther Plante $\$ 300$.

Petit Séminaire de Québec

Yvan Lortie

$\$ 200$.

CEGEP de Valleyfield

Patrice Nadeau
CEGEP de Valleyfield

$\$ 100$.

$\$ 100$.

$\$ 100$.

Le Ministre Jacques-Yvan Morin annonçait aux 500 convives réunis à Québec que le concours Lionel-Groulx, patronné à la fois par le Ministère de l'Éducation du Québec, le Haut Commissariat à la Jeunesse, aux Loisirs et aux Sports, la Fondation Lionel-Groulx et l'Institut d'histoire de l'Amérique française, deviendrait annuel.

Nos félicitations et nos remerciements à Monsieur Jacques Robitaille, responsable du concours auprès du Comité, maintenant président de la Société des professeurs d'histoire du Québec, qui a su mener à bien cette lourde tâche par une collaboration fort active, qui nous incite à la poursuite de l'expérience.

JULIETTE RÉMiLLARD secrétaire de la Fondation Lionel-Groulx 